

\title{
Huge Reduction of the Wake-Up Effect in Ferroelectric HZO Thin Films
}

Jordan Bouaziz, Pedro Rojo Romeo, Nicolas Baboux, Bertrand Vilquin

\section{To cite this version:}

Jordan Bouaziz, Pedro Rojo Romeo, Nicolas Baboux, Bertrand Vilquin. Huge Reduction of the Wake-Up Effect in Ferroelectric HZO Thin Films. ACS Applied Electronic Materials, 2019, 1 (9), pp.1740-1745. 10.1021/acsaelm.9b00367 . hal-02303151

\section{HAL Id: hal-02303151 \\ https://hal.science/hal-02303151}

Submitted on 22 Jun 2021

HAL is a multi-disciplinary open access archive for the deposit and dissemination of scientific research documents, whether they are published or not. The documents may come from teaching and research institutions in France or abroad, or from public or private research centers.
L'archive ouverte pluridisciplinaire HAL, est destinée au dépôt et à la diffusion de documents scientifiques de niveau recherche, publiés ou non, émanant des établissements d'enseignement et de recherche français ou étrangers, des laboratoires publics ou privés. 


\title{
${ }_{1}$ Huge Reduction of the Wake-Up Effect in Ferroelectric HZO Thin ${ }_{2}$ Films
}

\author{
3 Jordan Bouaziz, ${ }^{* \dagger, \ddagger \odot P ~ P e d r o ~ R o j o ~ R o m e o, ~}{ }^{\dagger}$ Nicolas Baboux, ${ }^{\ddagger}$ and Bertrand Vilquin ${ }^{\dagger}$ \\ $4{ }^{\dagger}$ Université de Lyon, Institut des Nanotechnologies de Lyon (UMR5270/CNRS), Ecole Centrale de Lyon, 36 avenue Guy de \\ 5 Collongue, F-69134 Ecully Cedex, France \\ ${ }_{6}$ "Université de Lyon, Institut des Nanotechnologies de Lyon (UMR5270/CNRS), INSA, Bât. Blaise Pascal, 7 avenue Jean Capelle, \\ 7 F-69621 Villeurbanne Cedex, France
}

9 ABSTRACT: The wake-up effect is a major issue for ferroelectric $\mathrm{HfO}_{2}$-based 10 memory devices. Here, two TiN/HZO/TiN structures deposited by magnetron 11 sputtering on silicon are compared. The maximum remanant polarization is 12 higher than $21 \mu \mathrm{C} / \mathrm{cm}^{2}$ for both samples, but a strong difference is observed in 13 the electrical behavior. For the mesa sample, the difference between the 14 maximum and initial remanent polarization is only $3 \mu \mathrm{C} / \mathrm{cm}^{2}$, whereas it is 15 around $14 \mu \mathrm{C} / \mathrm{cm}^{2}$ in the non-mesa case. We discuss the root causes of these 16 behaviors in light of GIXRD results.

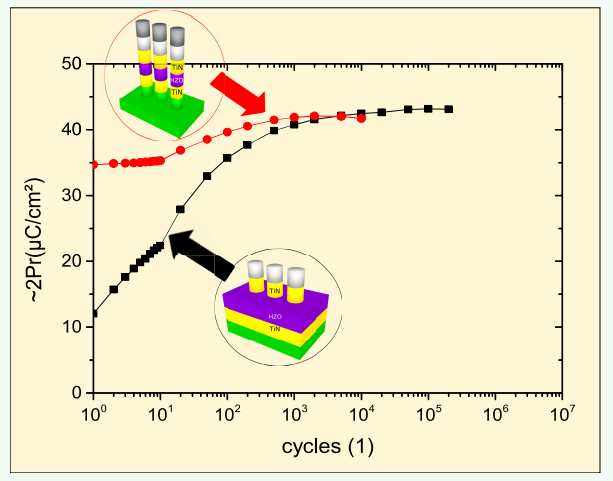

17 KEYWORDS: $\mathrm{HfO}_{2}, \mathrm{ZrO}_{2}, \mathrm{HZO}$, ferroelectricity, wake-up effect, FRAM

${ }_{18} 7$ he discovery of ferroelectric Si-doped $\mathrm{HfO}_{2}{ }^{1}$ has paved 19 the way to a wide variety of research interests and 20 technical developments. The growing number of papers 21 dealing with $\mathrm{HfO}_{2}$-based materials ${ }^{2}$ is a relevant indicator of 22 the growing interest for this subject. Undeniably, many 23 applications could benefit from ferroelectric $\mathrm{HfO}_{2}$-based 24 materials such as ferroelectric random access memory 25 (FRAM), a ferroelectric field effect transistor (FeFET), a 26 negative capacitance field effect transistor (NCFET), a 27 ferroelectric tunnel junction (FTJ), synaptic devices, pyro28 electric energy harvesters, piezoelectric devices, and so on. 29 However, major issues are still hindering the appearance of 30 ferroelectric $\mathrm{HfO}_{2}$-based materials on the market. These issues 31 are mainly related to the well-known wake-up effect, imprint, 32 fatigue, and endurance. Recent studies on the subject point out 33 crystallographic phase change and oxygen vacancy diffusion 34 during cycling as the root causes of the issues cited above.

35 Of all the numerous dopants that have been tested in 36 ferroelectric $\mathrm{HfO}_{2}$-based materials, the most addressed is 37 probably $\mathrm{Zr}^{4+}$, because both $\mathrm{HfO}_{2}$ and $\mathrm{ZrO}_{2}$ are already used 38 in the $\mathrm{CMOS}^{3}$ and $\mathrm{DRAM}^{4}$ industries. Moreover, $\mathrm{Zr}^{4+}$ allows 39 the lowest annealing temperature of all dopants, making it 40 compatible with the silicon semiconductor industry.

41 Compared to the hundreds of articles dealing with ( $\mathrm{Hf}$, $42 \mathrm{Zr}) \mathrm{O}_{2}$ solid solutions ( $\mathrm{HZO}$ ) deposited by ALD, sputtering 43 has rarely been used. ${ }^{5-14}$ However, the deposition of materials 44 by sputtering shows many benefits compared to ALD:

45 (i) Sputtering can be much faster than ALD deposition. (ii) Sputtering can prevent carbon contamination that 46 cannot be avoided with ALD precursors.

(iii) The deposition can be performed at room temperature. 48

(iv) In principle, sputtering can be carried out in one run in 49 the same sputtering chamber.

(v) Sputtering is a low-cost reproducible process. 51

Consequently, HZO development could be greatly 52 enhanced by using sputtering.

Moreover, most of the articles dealing with HZO sputtering 54 use cosputtering. $^{7-9,11,13,14}$ Cosputtering enables more param- 55 eters to be tuned, particularly the $\mathrm{Zr}$ doping. ${ }^{11}$ However, for 56 industrial manufacturing, single target sputtering appears to be 57 simpler and less expensive.

In this work, two different structures were realized by 59 magnetron sputtering with a single target. Their performances 60 are among the best in sputtering, but their behaviors are 61 completely different. Particularly, the mesa structure presents a 62 significantly reduced wake-up effect. We discuss the origins of 63 these differences and the consequences for electrical measure- 64 ment methods used to characterize ferroelectric $\mathrm{HfO}_{2}$-based 65 materials.

The structure shown in Figure 1a is called NM-sample for $67 \mathrm{fl}$ "non-mesa" structure and the structure shown in Figure $1 \mathrm{~b}$ is 68 called M-sample for "mesa” structure.

Received: June 11, 2019

Accepted: August 23, 2019

Published: August 23, 2019 

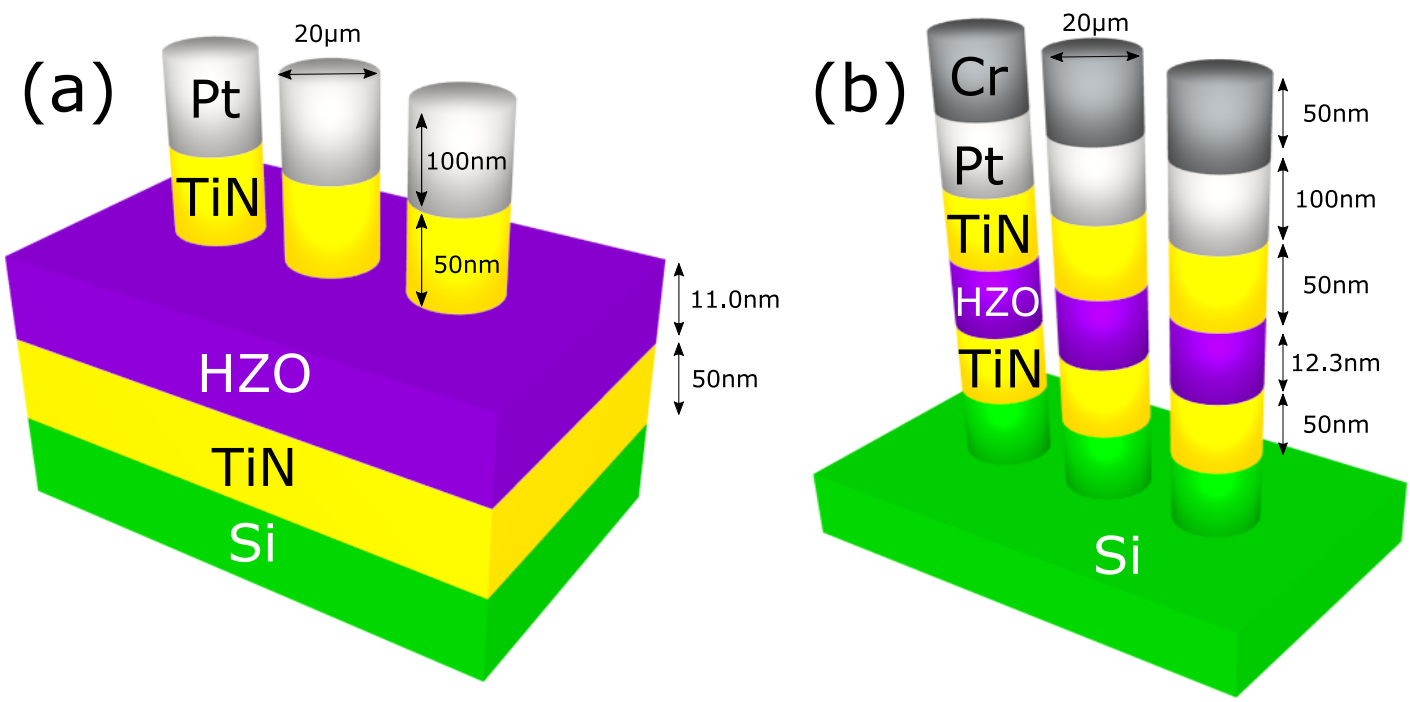

Figure 1. Scheme of (a) the NM-sample and (b) M-sample.

$70 \mathrm{Si}$ substrates were cleaned with ultrasonication in acetone 71 and ethanol for $1 \mathrm{~min}$. Substrates are Si-doped and (100)72 oriented. The native oxide layer of each substrate is removed 73 by a buffer oxide etch (BOE) process. For both processes, a 50 $74 \mathrm{~nm}$-thick bottom electrode (BE) is deposited in the conditions 75 detailed in Table 1. This layer blankets the entire Si substrate.

\section{Table 1. Film Growth Conditions for TiN and HZO}

\begin{tabular}{|c|c|c|}
\hline \multicolumn{3}{|c|}{ sputtering } \\
\hline target-substrate distance & $8 \mathrm{~cm}$ & \\
\hline base pressure & $<5 \times 1^{-7} \mathrm{mbar}$ & \\
\hline deposited elements & $\mathrm{TiN}$ & $(\mathrm{Hf}, \mathrm{Zr}) \mathrm{O}_{2}$ \\
\hline substrate & $\mathrm{Si}$ & $\mathrm{Si} / \mathrm{TiN}$ \\
\hline target & $\mathrm{Ti}$ & $\mathrm{ZrO}_{2} / \mathrm{HfO}_{2}(50 / 50)$ \\
\hline target RF power & $300 \mathrm{~W}$ & $100 \mathrm{~W}$ \\
\hline holder DC bias voltage & $60 \mathrm{~V}$ & none \\
\hline gas & $\mathrm{Ar}=50 \mathrm{sccm}$ & $\mathrm{Ar}=50 \mathrm{sccm}$ \\
\hline & $\mathrm{N}_{2}=3 \mathrm{sccm}$ & \\
\hline working pressure & $5 \times 10^{-3} \mathrm{mbar}$ & $5 \times 10^{-2} \mathrm{mbar}$ \\
\hline deposition speed & $5.2 \mathrm{~nm} / \mathrm{min}$ & $5 \mathrm{~nm} / \mathrm{min}$ \\
\hline \multicolumn{3}{|c|}{ rapid thermal annealing (RTA) conditions } \\
\hline temperature & \multicolumn{2}{|c|}{$450^{\circ} \mathrm{C}$} \\
\hline atmosphere & \multicolumn{2}{|l|}{$\mathrm{N}_{2}$} \\
\hline duration & \multicolumn{2}{|c|}{$30 \mathrm{~s}$} \\
\hline
\end{tabular}

76 Then, an HZO layer covering the whole TiN layer is 77 deposited. The HZO thickness is measured by X-ray 78 reflectivity (XRR). HZO layers are $12.3 \mathrm{~nm}$-thick and 11.0 $79 \mathrm{~nm}$-thick for the M-sample and the NM-sample, respectively. 80 For the NM-sample, UV photolithography is carried out. 81 Then, a $50 \mathrm{~nm}$-thick TiN TE followed by a $100 \mathrm{~nm}$ Pt top 82 electrode for mechanical and electrical contact are deposited. A 83 lift-off step is then performed. Finally, the NM-sample is 84 annealed by RTA under the conditions described in Table 1. It 85 means that, for the NM-sample, HZO is only partially covered 86 during the RTA crystallization process.

87 For the M-sample, the HZO layer is blanketed with a $50 \mathrm{~nm}$ 88 thick TiN layer. Then, UV photolithography and lift-off are 89 carried out to define the electrodes with the deposition of a $90100 \mathrm{~nm}$-thick Pt layer followed by a $50 \mathrm{~nm}$-thick $\mathrm{Cr}$ layer. $\mathrm{Cr}$ is 91 used as a hard mask for etching. The M-sample is annealed by
RTA in the conditions described in Table 1. Finally, the 92 sample is etched by RIE at $300 \mathrm{~W}$ (RF) for 20 min with $\mathrm{SF}_{6}$ as 93 a reactive gas. The final structure is presented in Figure $1 \mathrm{~b}$. For 94 this structure, HZO is fully covered with TiN TE during the 95 annealing step.

GIXRD is performed on a four-circle Smartlab Rigaku 97 diffractometer using a $9 \mathrm{~kW}$ copper rotating anode. 98

Electrical characterization is carried out on $20 \mu \mathrm{m}$ diameter 99 capacitors using a probe station and a setup composed of an 100 arbitrary waveform generator (Nippon Factory WF1966), a 101 transimpedance current amplifier (Keithley 428), and a 12 bit 102 Digital Storage Oscilloscope (Nicolet Integra 40).

103

Endurance tests were performed with bipolar square pulses 104 (commonly called set/reset sequence) until breakdown. The 105 set/reset sequence is achieved in two different configurations: 106 $2.5 \mathrm{kHz} / 3.5 \mathrm{~V}$ and $1.0 \mathrm{MHz} / 3.0 \mathrm{~V}$. The first sequence allows 107 the stress to be maximized without breakdown. The second 108 set/reset sequence is used in order to be as close as possible to 109 the microelectronic standard, and it is therefore used as a 110 reference.

$P-E$ curves are obtained using the PUND technique. This 112 consists of applying a negative set pulse followed by two 113 positive pulses ( $\mathrm{P}$ and $\mathrm{U}$ ) and then two negative pulses ( $\mathrm{N}$ and 114 D). The PUND maximum amplitude voltage equals that of the 115 set/reset sequence. PUND pulses are triangular pulses with a 116 rise/fall time of $100 \mu \mathrm{s}$, corresponding to $2.5 \mathrm{kHz} 117$ $\left(=\frac{1}{4 \times 100} \mu \mathrm{s}^{-1}\right)$.

First, the change of the sum of the absolute values of the 118 positive remanent polarization and the negative remanent 119 polarization $\left|P_{\mathrm{r}+}\right|+\left|P_{\mathrm{r}-}\right|$ during cycling is studied. Figure $2120 \mathrm{f} 2$ shows the results for the two different set/reset sequences 121 described in the experimental section.

122

At $1.0 \mathrm{MHz}$ and $3.0 \mathrm{~V}$ (Figure $2 \mathrm{a}$ ), $\left|P_{\mathrm{r}+}\right|+\left|P_{\mathrm{r}-}\right|$ for the NM- 123 sample starts at around $5 \mu \mathrm{C} / \mathrm{cm}^{2}$. This value increases until 124 $10^{5}$ cycles, where it reaches around $29 \mu \mathrm{C} / \mathrm{cm}^{2}$. Then, it 125 decreases until breakdown. Such an effect is not observable for 126 the M-sample. Indeed, $\left|P_{\mathrm{r}+}\right|+\left|P_{\mathrm{r}-}\right|$ starts at $25 \mu \mathrm{C} / \mathrm{cm}^{2}$ (instead 127 of $5 \mu \mathrm{C} / \mathrm{cm}^{2}$ for the NM-sample) and reaches a maximum of 128 $32.8 \mu \mathrm{C} / \mathrm{cm}^{2}$ at $2 \times 10^{3}$ cycles. So, the wake-up effect can be 129 considered negligible in these conditions. Subsequently, fatigue 130 


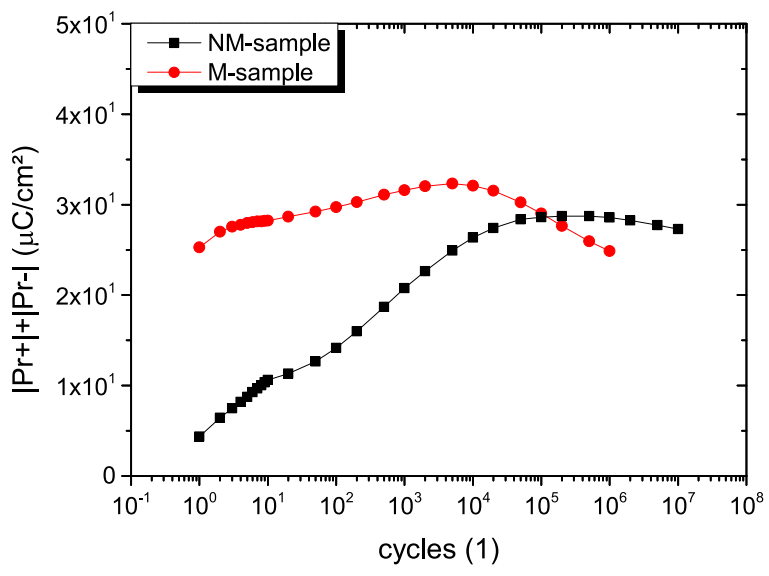

(a)

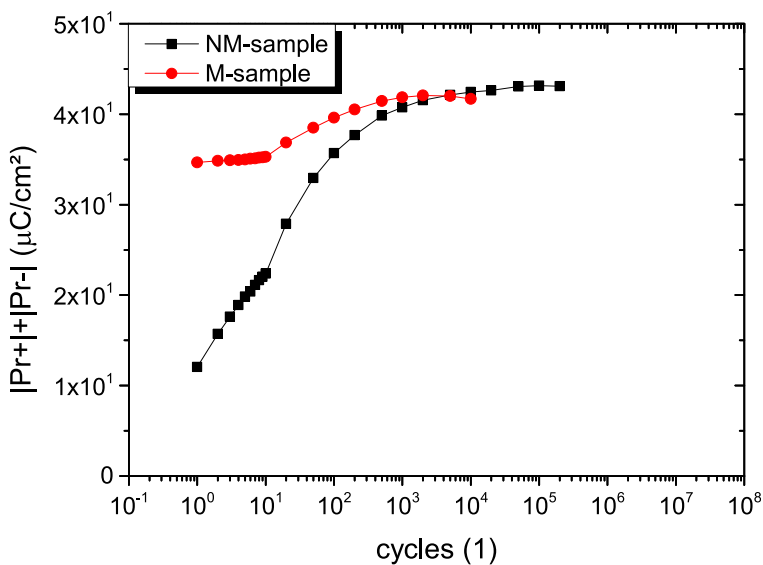

(b)

Figure 2. Change of $\left|P_{\mathrm{r}+}\right|+\left|P_{\mathrm{r}-}\right|$ versus the number of cycles with the stress conditions (a) $1.0 \mathrm{MHz}$ and $3.0 \mathrm{~V}$ and (b) $2.5 \mathrm{kHz}$ and $3.5 \mathrm{~V}$ for the NM-sample (black curve) and M-sample (red curve).

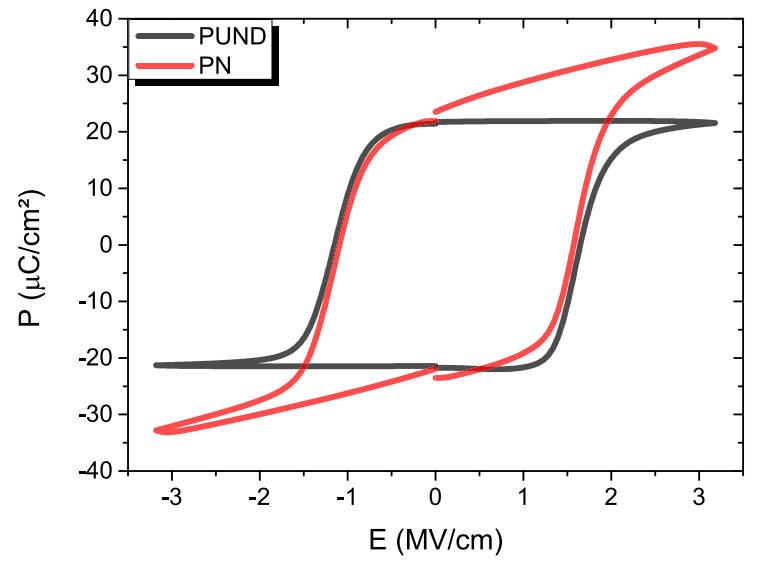

(a)

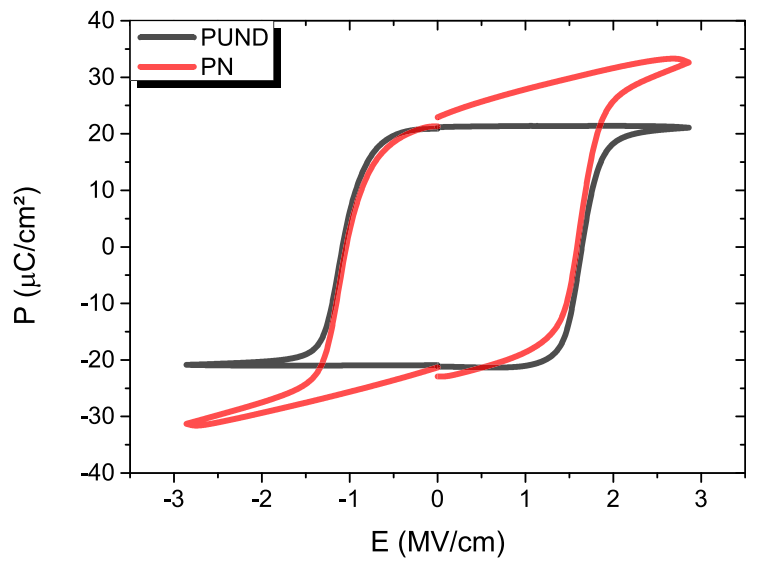

(b)

Figure 3. Polarization versus applied electrical field for (a) the NM-sample at $10^{5}$ cycles and (b) the M-sample at $2 \times 10^{3}$ cycles under the stress conditions: $2.5 \mathrm{kHz}$ and $3.5 \mathrm{~V}$.

131 begins and breakdown occurs after $5 \times 10^{5}$ cycles. In 132 comparison, the NM-sample breaks down after $1 \times 10^{7}$ cycles. 133 More severe stress conditions were also applied (Figure 2b). 134 The same tendencies are observed: here, the wake-up effect is 135 also significantly reduced on the M-sample compared to that 136 on the NM-sample, but it is detrimental for the endurance of 137 the M-sample. In fact, the breakdown occurs at a lower number 138 of cycles for the M-sample compared to for the NM-sample. 139 For both samples, $\left|P_{\mathrm{r}+}\right|+\left|P_{\mathrm{r}-}\right|$ values are much higher at 2.5 $140 \mathrm{kHz} / 3.5 \mathrm{~V}$ and the breakdown occurs earlier. These results are 141 consistent with previous observations. ${ }^{15-17}$

142 For both stress conditions, the $P_{\mathrm{r}}$ of the NM-sample 143 increases until it exceeds the $P_{\mathrm{r}}$ of the M-sample for a given 144 number of cycles, because fatigue occurs earlier for the M145 sample. As a consequence, at $1.0 \mathrm{MHz} / 3.0 \mathrm{~V}$ (Figure 3a), 146 between the first cycle and the breakdown, the $\mathrm{M}$-sample has a 147 higher maximum $P_{\mathrm{r}}=16.4 \mu \mathrm{C} / \mathrm{cm}^{2}$ than the NM-sample, 148 whereas at $2.5 \mathrm{kHz} / 3.5 \mathrm{~V}$ (Figure $2 \mathrm{~b}$ ), the M-sample has a 149 higher maximum $P_{\mathrm{r}}=21.7 \mu \mathrm{C} / \mathrm{cm}^{2}$. This is due to the 150 reduced wake-up effect. In fact, with the M-sample, the 151 maximum remanent polarization is always reached very rapidly, 152 whereas with the NM-sample, the higher the stress conditions, 153 the faster you can reach the maximum remanent polarization.
Moreover, for the NM-sample, fatigue is always reached at 154 around $10^{6}$ cycles, which means that under a low-stress 155 sequence, fatigue is reached on the NM-sample before crossing 156 the curve of the M-sample. It follows that the M-sample has a 157 higher remanent polarization under low-stress conditions, 158 whereas the NM-sample has a higher maximum remanent 159 polarization under high-stress conditions. Therefore, the 160 maximum $P_{\mathrm{r}}$ seems to be more dependent on the stress 161 conditions than on the structures themselves, which could have 162 important consequences on industrial applications. 163

The M-sample has a reduced wake-up effect, but it also 164 shows a sign of fatigue before the NM-sample. It is possible 165 that the M-sample is already in an awake state, which leads to 166 the absence of wake-up and an earlier fatigue and breakdown 167 compared to the NM-sample.

For the M-sample, the maximum $P_{\mathrm{r}}$ minus the initial $P_{\mathrm{r}}$ is 169 around 3-4 $\mu \mathrm{C} / \mathrm{cm}^{2}$ in both conditions. In comparison, the 170 difference is between 12 and $16 \mu \mathrm{C} / \mathrm{cm}^{2}$ for the NM-sample. 171 There is 1 order of magnitude between both increases of $P_{\mathrm{r}} 172$ during the wake-up.

In high-stress conditions, there is no double peak for the M- 174 sample, and in low-stress conditions, the double peak 175 disappears at the second measurement cycle. For the NM- 176 


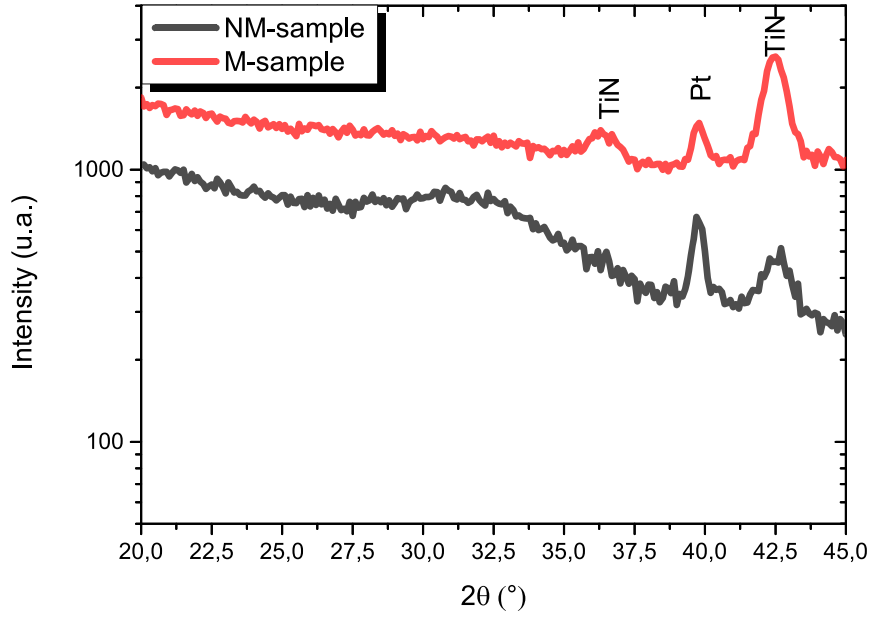

(a)

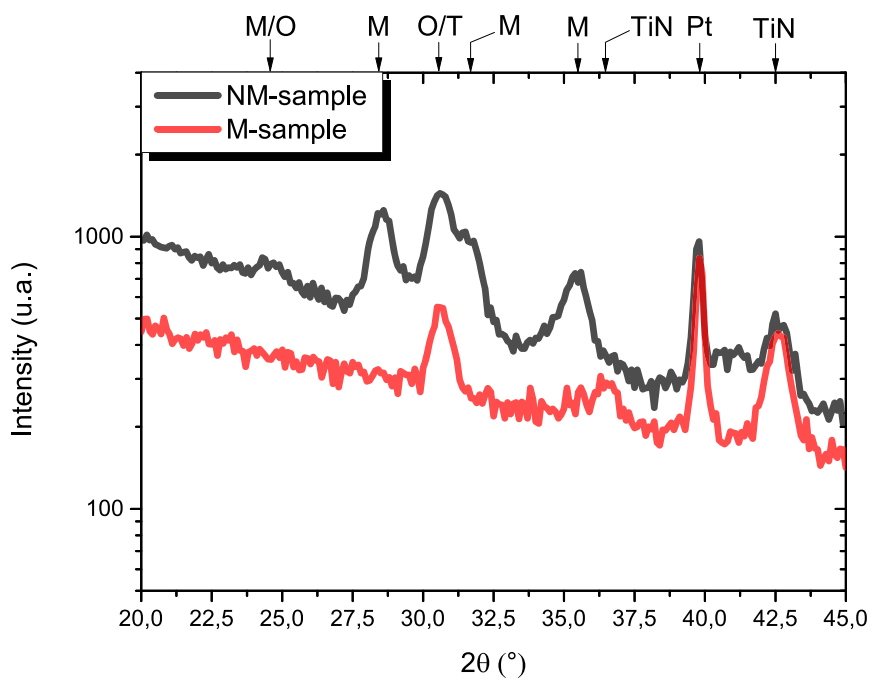

(b)

Figure 4. GIXRD measurements comparing the NM-sample (black curve) and the M-sample (red curve) (a) before RTA and (b) after RTA. M stands for monoclinic, $\mathrm{O}$ stands for orthorhombic, and $\mathrm{T}$ stands for tetragonal phases.

177 sample, a double peak is clearly observable during the first 178 measurement cycle, and a small peak (coming from the double 179 peak) is observable until $10^{3}$ cycles for high-stress conditions 180 and until $5 \times 10^{4}$ cycles for low-stress conditions (see the 181 Supporting Information for more details).

182 Finally, at 10 cycles, an inflection point can be seen. It is 183 caused by the measurements realized due to the PUND 184 technique, which also wakes the sample. The PUND 185 measurement is negligible after 20 cycles, as compared to the $186 \mathrm{set} /$ reset cycles.

187 It is to be noted that these results have been reproduced on 188 many electrodes.

189 To assess the quality of our films, Figure 3 shows the 190 polarization versus the electrical field when $P_{\mathrm{r}}$ has reached its 191 maximum value. PUND and PN curves are represented. The 192 value of $P_{\mathrm{r}}$ is higher in $\mathrm{PN}$ curves, because $\mathrm{PN}$ includes the 193 leakage current. $P_{\mathrm{r}}$ values of the $\mathrm{PN}$ measurements have not 194 been discussed in this report, because they can include 195 extrinsic effects. Leakage is very well-compensated, because the 196 PN curves show open cycles, whereas PUND does not. Also, 197 the $P-E$ curves by PUND show very pinched cycles, which 198 means that the samples are very well-saturated.

199 Then, grazing incidence X-ray diffraction is carried out to 200 enlighten the electrical characterizations. Figure 4 shows 201 GIXRD results before (Figure 4a) and after (Figure 4b) 202 annealing of the NM-sample and the M-sample. ICDD card 203 nos. 00-038-1420 and 00-004-0802 were respectively used for 204 TiN and Pt. For the HZO m-phase, ICDD card no. 04-0022055428 was used. The peak at around $30.5^{\circ}$ for the o/t-phase 206 came from the work of Lee et al., ${ }^{8}$ and we knew from the first 207 paper on ferroelectricity in hafnium oxide by Böscke et al. ${ }^{1}$ that 208 a peak at around $25^{\circ}$ can be mistaken with the peak coming 209 from the m-phase at this angle. In Figure 4a, the M-sample 210 presents a TiN(111) peak, which is not visible in the NM211 sample. This is probably caused by the different structures of 212 the TiN TE in each sample. Comparing the NM-sample and 213 the $\mathrm{M}$-sample in Figure $4 \mathrm{~b}$, it is clear that the polycrystalline 214 nature of the samples is completely different. The NM-sample 215 shows clear monoclinic phases (m-phases), whereas no 216 monoclinic peak can be seen in the M-sample. On the M- sample, only the o(111) peak can be seen. Other peaks come 217 from the electrodes. 218

At the microcrystalline scale, the orthorhombic phase (o- 219 phase) is recognized as the origin of ferroelectricity. m-Phases 220 are assumed to be parasitic phases for ferroelectricity. Two 221 hypotheses are generally considered as the causes of the wake- 222 up effect according to Fengler et al: ${ }^{18}$ crystallographic phase 223 change contributions and oxygen vacancy diffusion. Grimley et 224 al. ${ }^{19}$ have observed a phase transition from the $\mathrm{m}$ - to the $\mathrm{o}-225$ phase using scanning transmission electron microscopy 226 (STEM) and impedance spectroscopy. Therefore, tremendous 227 reduction in the amount of $\mathrm{m}$-phase in the $\mathrm{M}$-sample could 228 have led to a drastic decrease in the wake-up effect. Moreover, 229 the presence of many monoclinic orientations coexisting with 230 the o-phase on the NM-sample could also play a key role in the 231 oxygen vacancy redistribution, because the number of 232 interfaces between crystallites has increased on the NM- 233 sample. In fact, the crystalline structure influences the 234 redistribution of charged defects, the mobility of these charges, 235 charge trapping, and charge screening. For that reason, it can 236 be concluded that the microcrystalline structure seems to be 237 the main parameter influencing the two different electrical 238 behaviors observed in this Letter.

One could argue that the different crystalline structures are 240 due to the TiN TE difference between the two samples. In fact, 241 in the case of the M-sample, TiN is blanketed over the entire 242 HZO layer, whereas in the case of the NM-sample, it covers 243 only the areas under the top electrodes. This implies a 244 completely different stress state between the two samples. As a 245 consequence, in the case of the M-sample, it turns the o-phase 246 into the lowest energy phase. It has actually been demonstrated 247 that TiN TE acts as a tensile stressor on the HZO film during 248 the annealing process. ${ }^{20-24}$ The stress inhibits the formation of 249 the monoclinic phase during HZO crystallization, forming an 250 orthorhombic phase that generates a large ferroelectric 251 polarization, even at low process temperatures. 252

Finally, Chernikova et al. ${ }^{25}$ compare the $P_{\mathrm{r}}$ performances of 253 an HZO layer and a La-doped HZO layer called "HZLO". The 254 $\mathrm{HZO}$ layer has a very low wake-up effect but also a very low 255 endurance, whereas HZLO has a very high endurance with a 256 
257 very high wake-up effect. The exact same phenomenon is 258 observed here when measuring the NM-sample and the M259 sample. Consequently, the root causes of the huge reduction of 260 the wake-up effect and the decreasing of cycles before 261 breakdown in both articles could be assumed to be the 262 same. However, they observed that "the HZLO film showed a 263 slightly larger grain size compared to the HZO film". 264 Consequently, according the authors of the article, "the bulk 265 free energy difference between the FE o-phase and non-FE m266 phase decreased after La doping." Unfortunately, this cannot 267 explain what is happening in our work, because the observation 268 of clear monoclinic peaks in the GIXRD pattern of the NM269 sample Figure $4 \mathrm{~b}$ suggests that the free energy difference 270 decreases. Manufacturing both structures with HZLO instead 271 of HZO may help to shed light on this mystery.

272 This Letter reports the fabrication of two samples deposited 273 by magnetron sputtering with excellent performances, quite 274 similar to samples deposited by ALD. ${ }^{25} P_{\mathrm{r}}$ values are among 275 the highest for samples deposited by sputtering.

276 Although the M-sample and the NM-sample show very 277 similar maximum $P_{\mathrm{r}}$ values, both samples demonstrate 278 completely different electrical behavior. During cycling, the 279 increase of the $P_{\mathrm{r}}$ value for the NM-sample is more than an 280 order of magnitude higher than that of the M-sample. It is 281 accompanied by a decrease of the endurance, which is 2 orders 282 of magnitude higher for the NM-sample than for the M283 sample.

284 As the electrical behaviors are not the same, for low-stress 285 conditions, the $\mathrm{M}$-sample has a higher maximum $P_{\mathrm{r}}$ value 286 during cycling, whereas for high-stress conditions, the NM287 sample has a higher $P_{\mathrm{r}}$ value during cycling. As a matter of fact, 288 it has been proven that maximum $P_{\mathrm{r}}$ values are more sensitive 289 to stress conditions than the to structures themselves.

290 The origins of the different electrical behaviors come from 291 the microcrystalline structures of the two samples, according to 292 GIXRD results. The crystallization takes place during the 293 annealing step. During annealing, the M-sample is built with a 294 TiN TE fully covering the HZO layer, whereas the TiN only 295 partially covers the HZO layer in the case of the NM-sample. It 296 induces different stress states, which lead to two different 297 microcrystalline patterning. The M-sample shows no mono298 clinic peak, whereas the NM-sample shows many monoclinic 299 orientations. This explains the huge reduction of the wake-up 300 effect.

\section{$301 \square$ ASSOCIATED CONTENT}

\section{S Supporting Information}

303 The Supporting Information is available free of charge on the 304 ACS Publications website at DOI: 10.1021/acsaelm.9b00367.

305 Chronograms for the M-sample and NM-sample 306 describing the presence, the absence, and the mergers 307 of the double peak obtained due to the PUND 308 measurements (PDF)

\section{$309 \square$ AUTHOR INFORMATION}

\section{Corresponding Author}

311 *E-mail: jordan.bouaziz@insa-lyon.fr.

312 ORCID

313 Jordan Bouaziz: 0000-0003-0975-5066

314 Notes

315 The authors declare no competing financial interest.

\section{ACKNOWLEDGMENTS}

316

This work was realized on the NanoLyon technology platform 317 and has received funding from the European Union's Horizon 318 2020 Research and Innovation Programme under grant 319 agreement $\mathrm{n}^{\circ}$ 780302. We also thank GDR OxyFun for its 320 financial support. We also thank Ruben Vera, Erwann Jeanneau 321 (Centre de Diffractométrie Henri Longchambon, Université de 322 Lyon), and Ingrid Cañero Infante (Institut des Nano- 323 technologies de Lyon) for their help in the XRD data analysis. 324

\section{REFERENCES}

(1) Böscke, T. S.; Müller, J.; Bräuhaus, D.; Schröder, U.; Böttger, U. 326 Ferroelectricity in Hafnium Oxide Thin Films. Appl. Phys. Lett. 2011, 327 99, 102903.

328

(2) Park, M. H.; Lee, Y. H.; Mikolajick, T.; Schroeder, U.; Hwang, 329 C. S. Review and Perspective on Ferroelectric $\mathrm{HfO}_{2}$-based Thin Films 330 for Memory Applications. MRC 2018, 8, 795-808.

331

(3) Kim, K. From the Future Si Technology Perspective: Challenges 332 and Opportunities. 2010 IEEE International Electron Devices Meeting 333 (IEDM) 2010, 1.1.1-1.1.9.

334

(4) James, D. Recent Innovations in DRAM Manufacturing. 2010335 21st Annual IEEE/SEMI Advanced Semiconductor Manufacturing 336 Conference (ASMC) 2010, 264-269.

337

(5) Kiguchi, T.; Nakamura, S.; Akama, A.; Shiraishi, T.; Konno, T. J. 338 Solid State Epitaxy of (Hf,Zr) $\mathrm{O}_{2}$ Thin Films with Orthorhombic 339 Phase. J. Ceram. Soc. Jpn. 2016, 124, 689-693.

340

(6) Fan, Z.; Xiao, J.; Wang, J.; Zhang, L.; Deng, J.; Liu, Z.; Dong, Z.; 341 Wang, J.; Chen, J. Ferroelectricity and Ferroelectric Resistive 342 Switching in Sputtered $\mathrm{Hf}_{0.5} \mathrm{Zr}_{0.5} \mathrm{O}_{2}$ Thin Films. Appl. Phys. Lett. 343 2016, 108, 232905.

(7) Ambriz-Vargas, F.; Kolhatkar, G.; Broyer, M.; Hadj-Youssef, A.; 34 Nouar, R.; Sarkissian, A.; Thomas, R.; Gomez-Yáñez, C.; Gauthier, M. 346 A.; Ruediger, A. A Complementary Metal Oxide Semiconductor 347 Process-Compatible Ferroelectric Tunnel Junction. ACS Appl. Mater. 348 Interfaces 2017, 9, 13262-13268.

(8) Lee, Y. H.; Kim, H. J.; Moon, T.; Kim, K. D.; Hyun, S. D.; Park, 350 H. W.; Lee, Y. B.; Park, M. H.; Hwang, C. S. Preparation and 351 Characterization of Ferroelectric $\mathrm{Hf}_{0.5} \mathrm{Zr}_{0.5} \mathrm{O}_{2}$ Thin Films Grown by 352 Reactive Sputtering. Nanotechnology 2017, 28, 305703.

(9) Das, K.; Tripathy, N.; Ghosh, S.; Sharma, P.; Singhal, R.; Kar, J. 354 Microstructural, Surface and Interface Properties of Zirconium Doped 355 $\mathrm{HfO}_{2}$ Thin Films Grown by RF Co-sputtering Technique. Vacuum 356 2017, 143, 288-293.

357

(10) Ambriz-Vargas, F.; Kolhatkar, G.; Thomas, R.; Nouar, R.; 358 Sarkissian, A.; Gomez Yáñez, C.; Gauthier, M. A.; Ruediger, A. 359 Tunneling Electroresistance Effect in a $\mathrm{Pt} / \mathrm{Hf}_{0.5} \mathrm{Zr}_{0.5} \mathrm{O}_{2} / \mathrm{Pt}$ Structure. 360 Appl. Phys. Lett. 2017, 110, No. 093106.

(11) Migita, S.; Ota, H.; Yamada, H.; Shibuya, K.; Sawa, A.; 362 Toriumi, A. Polarization Switching Behavior of Hf Zr O Ferroelectric 363 Ultrathin films Studied Through Coer cive Field Characteristics. Jpn. 364 J. Appl. Phys. 2018, 57, No. 04FB01.

365

(12) Bouaziz, J.; Rojo Romeo, P.; Baboux, N.; Vilquin, B. 366 Characterization of Ferroelectric Hafnium/Zirconium Oxide Solid 367 Solutions Deposited by Reactive Magnetron Sputtering. J. Vac. Sci. 368 Technol., B: Nanotechnol. Microelectron.: Mater., Process., Meas., 369 Phenom. 2019, 37, No. 021203.

(13) Migita, S.; Ota, H.; Shibuya, K.; Yamada, H.; Sawa, A.; 371 Matsukawa, T.; Toriumi, A. Phase Transformation Behavior of 372 Ultrathin $\mathrm{Hf}_{0.5} \mathrm{Zr}_{0.5} \mathrm{O}_{2}$ Films Investigated Through Wide Range 373 Annealing Experiments. Jpn. J. Appl. Phys. 2019, 58, SBBA07. 374 (14) Luo, Q.; Ma, H.; Su, H.; Xue, K.-H.; Cao, R.; Gao, Z.; Yu, J.; 375 Gong, T.; Xu, X.; Yin, J.; Yuan, P.; Tai, L.; Dong, D.; Long, S.; Liu, 376 Q.; Miao, X.-S.; Lv, H.; Liu, M. Composition-Dependent Ferroelectric 377 Properties in Sputtered $\mathrm{Hf}_{\mathrm{X}} \mathrm{Zr}_{1-\mathrm{X}} \mathrm{O}_{2}$ Thin Films. IEEE Electron Device 378 Lett. 2019, 40, 570-573. 
380 (15) Zhou, D.; Xu, J.; Li, Q.; Guan, Y.; Cao, F.; Dong, X.; Müller, J.; 381 Schenk, T.; Schröder, U. Wake-up Effects in Si-doped Hafnium Oxide 382 Ferroelectric Thin Films. Appl. Phys. Lett. 2013, 103, 192904.

383 (16) Starschich, S.; Menzel, S.; Böttger, U. Pulse Wake-up and 384 Breakdown Investigation of Ferroelectric Yttrium doped $\mathrm{HfO}_{2}$. J. 385 Appl. Phys. 2017, 121, 154102.

386 (17) Starschich, S.; Menzel, S.; Böttger, U. Evidence for Oxygen 387 Vacancies Movement During Wake-up in Ferroelectric Hafnium 388 Oxide. Appl. Phys. Lett. 2016, 108, 032903.

389 (18) Fengler, F. P.; Hoffmann, M.; Slesazeck, S.; Mikolajick, T.; 390 Schroeder, U. On The Relationship Between Field Cycling and 391 Imprint In Ferroelectric $\mathrm{Hf}_{0.5} \mathrm{Zr}_{0.5} \mathrm{O}_{2}$. J. Appl. Phys. 2018, 123, 204101. 392 (19) Grimley, E. D.; Schenk, T.; Sang, X.; Pešić, M.; Schroeder, U.; 393 Mikolajick, T.; LeBeau, J. M. Structural Changes Underlying Field394 Cycling Phenomena in Ferroelec tric $\mathrm{HfO}_{2}$ Thin Films. Advanced 395 Electronic Materials 2016, 2, 1600173.

396 (20) Park, M. H.; Kim, H. J.; Kim, Y. J.; Jeon, W.; Moon, T.; Hwang, 397 C. S. Ferroelectric Properties and Switching Endurance of $398 \mathrm{Hf}_{0.5} \mathrm{Zr}_{0.5} \mathrm{O}_{2}$ Films on TiN Bottom and $\mathrm{TiN}$ or $\mathrm{RuO}_{2}$ Top Electrodes. 399 physica status solidi (RRL). Phys. Status Solidi RRL 2014, 8, 532-535. 400 (21) Hyuk Park, M.; Joon Kim, H.; Jin Kim, Y.; Moon, T.; Seong 401 Hwang, C. The Effects of Crystallographic Orientation and Strain of 402 Thin $\mathrm{Hf}_{0.5} \mathrm{Zr}_{0.5} \mathrm{O}_{2}$ Film on its Ferroelectricity. Appl. Phys. Lett. 2014, 403 104, No. 072901.

404 (22) Hyuk Park, M.; Joon Kim, H.; Jin Kim, Y.; Lee, W.; Kyeom 405 Kim, H.; Seong Hwang, C. Effect of Forming Gas Annealing on the 406 Ferroelectric Properties of $\mathrm{Hf}_{0.5} \mathrm{Zr}_{0.5} \mathrm{O}_{2}$ Thin Films with and without 407 Pt Electrodes. Appl. Phys. Lett. 2013, 102, 112914.

408 (23) Park, M. H.; Kim, H. J.; Kim, Y. J.; Lee, W.; Moon, T.; Kim, K. 409 D.; Hwang, C. S. Study on the Degradation Mechanism of the 410 Ferroelectric Properties of Thin $\mathrm{Hf0} 0.5 \mathrm{Zr}_{0.5} \mathrm{O}_{2}$ Films on TiN and Ir 411 Electrodes. Appl. Phys. Lett. 2014, 105, 072902.

412 (24) Kim, S. J.; Narayan, D.; Lee, J.-G.; Mohan, J.; Lee, J. S.; Lee, J.; 413 Kim, H. S.; Byun, Y. c.; Lucero, A. T.; Young, C. D.; Summerfelt, S. 414 R.; San, T.; Colombo, L.; Kim, J. Large Ferroelectric Polarization of $415 \mathrm{TiN} / \mathrm{Hf}_{0.5} \mathrm{Zr0.5O} \mathrm{O}_{2} / \mathrm{TiN}$ Capacitors Due to Stress-induced Crystal416 lization at Low Thermal Budget. Appl. Phys. Lett. 2017, 111, 242901. 417 (25) Chernikova, A. G.; Kozodaev, M. G.; Negrov, D. V.; 418 Korostylev, E. V.; Park, M. H.; Schroeder, U.; Hwang, C. S.; 419 Markeev, A. M. Improved Ferroelectric Switching Endurance of La420 Doped $\mathrm{Hf}_{0.5} \mathrm{Zr}_{0.5} \mathrm{O}_{2}$ Thin Films. ACS Appl. Mater. Interfaces 2018, 10, $4212701-2708$. 